\title{
Histopathological Types of Operable Early Breast Cancer in the Elderly: Is there a Special Pattern? - a Retrospective, Multicentre Study
}

\author{
Corresponding author: \\ Abdalla Saad Abdalla Al-Zawi, PhD \\ Department of Radiology, Basildon \& \\ Thurrock University Hospital \\ Nethermayne, SS16 5NL Basildon, \\ ESSEX \\ United Kingdom \\ e-mail: abdalasaad@gmail.com
}

Medical Research Journal 2018;

Volume 3, Number 1, 10-14

10.5603/MRJ.2018.0002

Copyright (c) 2018 Via Medica

ISSN 2451-2591

\begin{abstract}
Introduction: The aim of this study was to determine the pattern of histopathological types of breast cancer in women aged 70 years or more with operable early breast cancer, and its implication on the potential prognosis. Methodology \& Material: A retrospective cohort study included 170 patients hospitalised for breast cancer treatment in departments of surgery of two teaching hospitals (Basildon University Hospital, Basildon, United Kingdom, and Greater Poland Oncology Centre, Poznan, Poland).

Material and methods: All 170 patients underwent surgical management for breast cancer. Invasive ductal carcinoma (IDC) was the most common histopathological type in the study group (74\%). The mucinous carcinoma was seen in $1.7 \%$ of cases, invasive lobular carcinoma in only $1 \%$ of patients, while the ductal carcinoma in situ was present in $6.5 \%$ of subjects. Lympho-vascular invasion was detected in $23 \%$ of cases. Conclusion: Less aggressive histological pattern was predominantly detected in the elderly patients with breast cancers

Key words: Breast cancer, ductal carcinoma, lobular carcinoma, mucinous carcinoma, lympho-vascular invasion.
\end{abstract}

Med Res J 2018; 3 (1): 10-14

\section{Introduction}

It is well known that the incidence of breast cancer increases with age, and that this disease is a leading cause of death among women. Increased risk for breast cancer is associated with late first pregnancy, lack of breast feeding history, late menopause, use of hormonal replacement therapy (HRT), smoking and obesity [1]. The median age of breast cancer diagnosis is 60 years old, and over $40 \%$ of new cases are diagnosed in women aged 65 years or older [2]. It was suggested that advanced age may affect biological characteristics of breast cancer [3].

The available data indicate that breast cancer has a relatively good prognosis among the elderly patients, and unfavourable prognosis in young patients [4-6]. The literature reveals that invasive ductal carcinoma (Figure 1) accounts for $80 \%$ of breast cancer, and that lobular invasive carcinoma (Figure 2) and mucinous carcinoma are relatively more frequent in older patients [4] .It was reported that intra-cystic papillary carcinoma is more frequent in older patients [7].
The aim of this study was to review the histopathological tumour types in relation to age of patients with

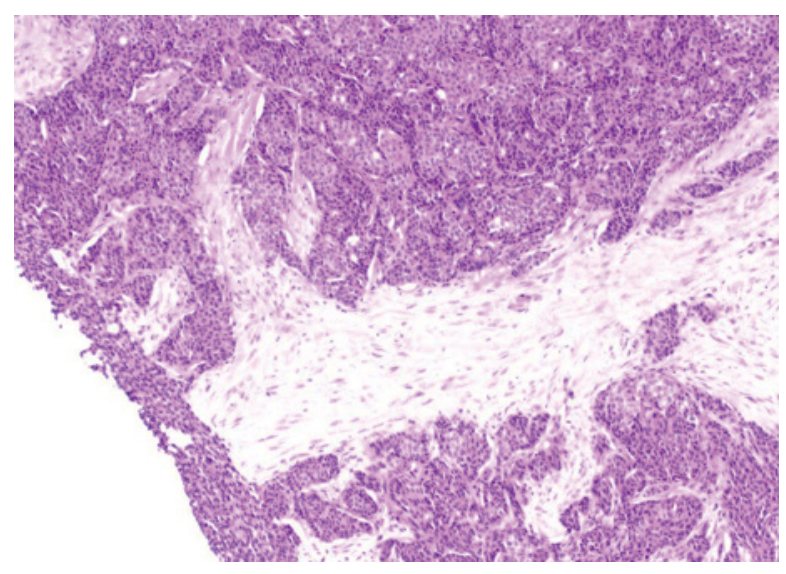

Figure 1. Grade 2 Invasive Ductal carcinoma of Breast.: Sheaths and nests of pleomorphic cells with cellular atypia and prominent mitotic figures 


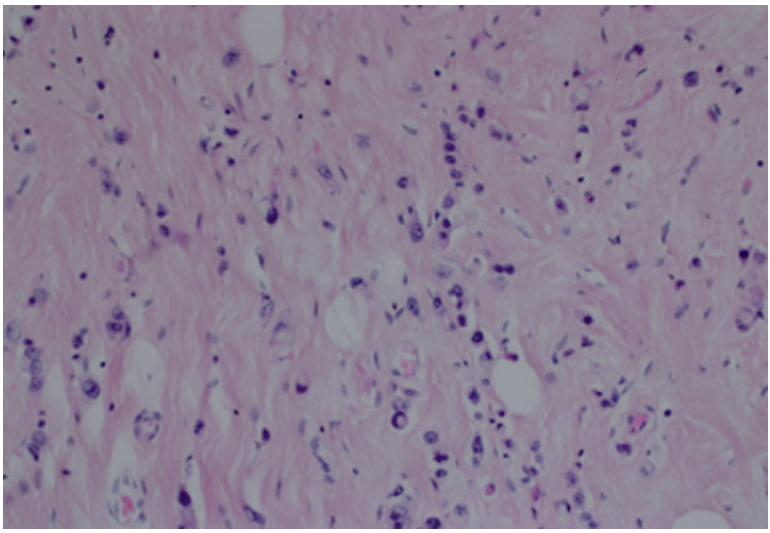

Figure 2. Breast invasive lobular carcinoma: single neoplastic cell infiltration of the stroma

breast cancer, and to determine potential indicators of more aggressive characteristics in different age groups.

\section{Patients and methods}

The study comprised of 170 women aged 70 years or more with invasive and non-invasive breast cancer who were treated surgically at the Breast Unit, Basildon University Hospital, Basildon, United Kingdom, and Greater Poland Oncology Centre, Poznan, Poland, between 2011 and 2016. Included patients had breast conservation procedure or mastectomy, and axillary surgery when indicated. The patients were divided into three age subgroups: $70-75$ years old, $76-80$ years old and above 80 years old. Patients with bilateral disease were included only once. We analysed the histopathological diagnosis, grade of the tumour in the invasive ductal carcinoma, and presence of lympho-vascular invasion, which was reported as present or absent.

\section{Results}

The age structure of the study population was: $70-75$ years old $-38 \%, 76-80$ years old $-38 \%$, and above 80 years old $-24 \%$, as shown in Table 1 . Invasive ductal carcinoma (IDC) was the most common histopathological type in the study group, and accounted for $74 \%$ cases of breast cancer (Figures 3 and 4 ). In this subgroup, it was noticed that grade 2 IDC was the most frequent $(35 \%)$, followed by grade 3 IDC $(24 \%)$ and grade 1 IDC (15\%). In the examined cohort, invasive lobular carcinoma was present in $10 \%$ of cases, and mucinous carcinoma was seen in only $1.7 \%$ of cases, whereas ductal carcinoma in situ occurred in $6.5 \%$ of patients. The lympho-vascular invasion was present in $23 \%$ of all cases and absent in $69 \%$. It was not applicable in $7 \%$ of cases which were invasive ductal carcinoma in situ, (Figure 5).

\section{Discussion}

Breast cancer is the most common human neoplasm with more than 1,000,000 cases occurring worldwide annually [8], the most common malignant disease in women worldwide (25\%), that accounts for $27 \%$ of cancers in developed countries, and is the leading cause of mortality in women [9-11]. The number of elderly breast cancer patients is rising as a result of increase in the aged population. Advanced age is a known risk factor for the breast cancer. An increased risk for breast cancer is observed if the advanced age is associated with late first pregnancy, lack of breast feeding history, late menopause, use of HRT, smoking and obesity $[1,12]$. The average age at the time of breast cancer diagnosis is 61 years, and the majority of breast cancer related deaths occur at age of 65 years or older. Only about $30-35 \%$ of patients with breast cancer are older than 70 years of age, while approximately $45-50 \%$ are

Table 1. Invasive and non-invasive breast neoplasm in patients above 70 years of age.

\begin{tabular}{lcccc}
\hline \multicolumn{3}{c}{ Results } \\
\hline sAge Group & $\mathbf{7 0 - 7 5}$ Yrs & $\mathbf{7 6 - 8 0}$ Yrs & $>\mathbf{8 0}$ Yrs & Total \\
\hline Total & $65[38.2 \%]$ & $65[38.2 \%]$ & $40[23.5 \%]$ & $170[110 \%]$ \\
Invasive Ductal Carcinoma (IDC) & $44[25.8 \%]$ & $54[31.7 \%]$ & $29[17 \%]$ & $127[74.7 \%]$ \\
Grade I IDC & $11[6.47 \%]$ & $11[6.47 \%]$ & $5[2.94 \%]$ & $27[15.8 \%]$ \\
Grade II IDC & $21[12.3 \%]$ & $24[14.1 \%]$ & $14[8.23 \%]$ & $59[34.7 \%]$ \\
Grade IIII IDC & $12[7.05 \%]$ & $19[11.1 \%]$ & $10[5.88 \%]$ & $41[24.1 \%]$ \\
Invasive Lobular Carcinoma (ILC) & $8[4.70 \%]$ & $4[2.35 \%]$ & $5[2.94 \%]$ & $17[10 \%]$ \\
Mucinous & $0[0 \%]$ & $2[[1.17 \%]$ & $1[0.588 \%]$ & $3[1.76 \%]$ \\
Mixed + Other & $7[4.11 \%]$ & $3[1.76 \%]$ & $1[0.588 \%]$ & $11[6.47 \%]$ \\
Ductal Carcinoma in situ & $6[3.52 \%]$ & $2[1.17 \%]$ & $4[2.35 \%]$ & $12[7.05 \%]$ \\
\hline
\end{tabular}




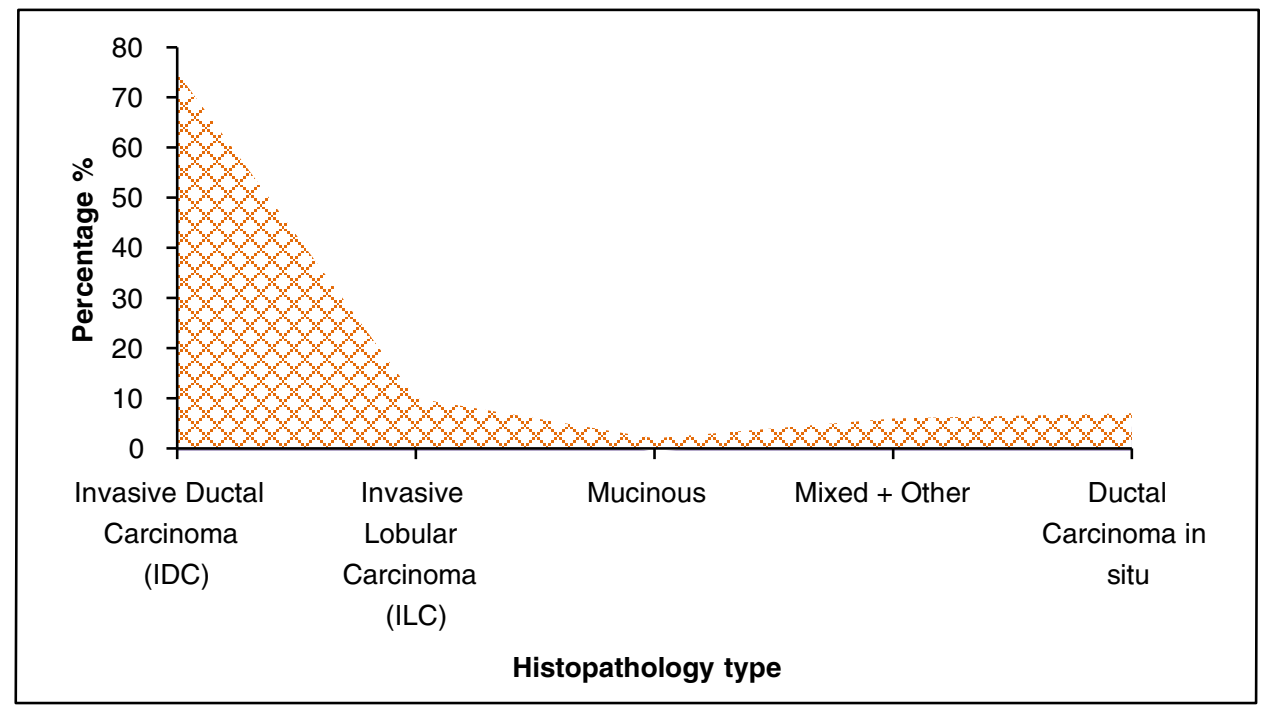

Figure 3. Histopathology of operated breast cancer in 170 patients aged above 70 years

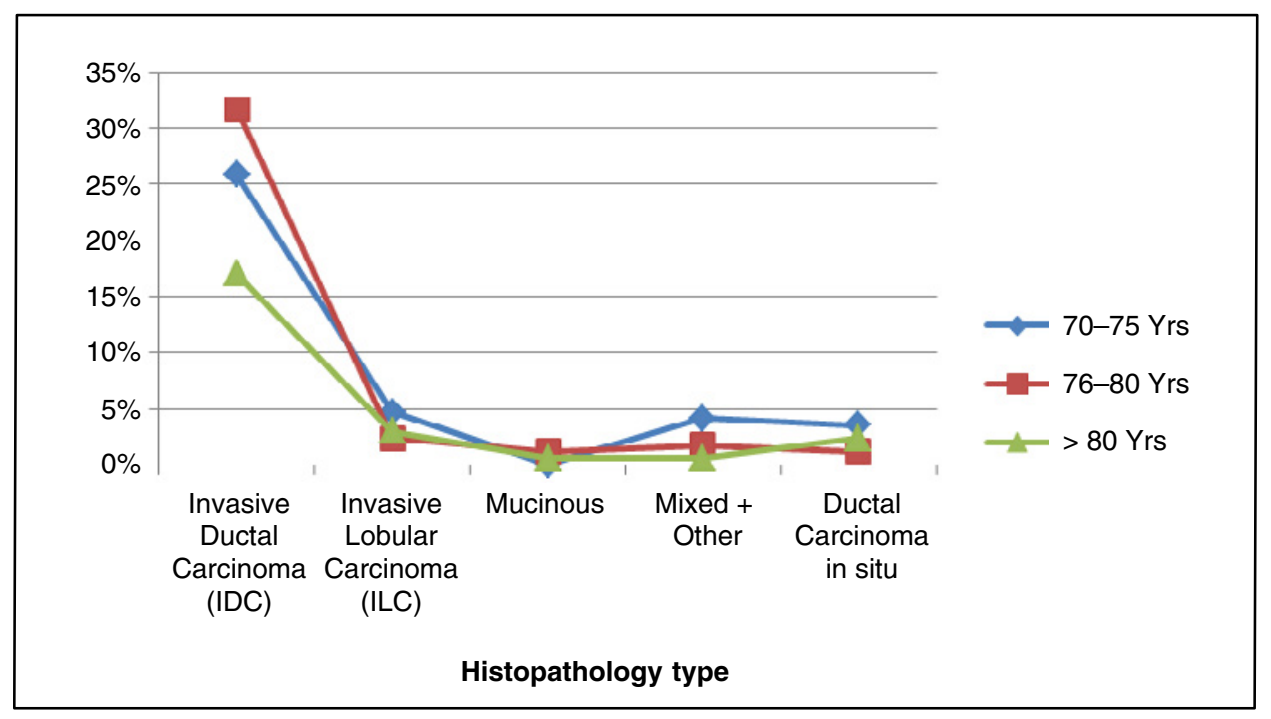

Figure 4. Histopathological Types of Breast Cancer in Operated 170 females all aged above 70 years- distribution in age subgroups

65 years or older $[1,13]$. There are reports that, with advanced age breast cancer may change its biological characteristics. The studies suggest that advanced age might be associated with more favourable tumor biology [14], and that breast cancer has a relatively good prognosis among the elderly patients, while the prognosis is less favourable in younger patients [4-6]. Breast cancer is well known to be a heterogeneous disease with multiple pathological varities associated with distinctive histopathological features. Breast cancer is divided into carcinoma in situ and invasive adenocarcinoma. In carcinoma in situ, the neoplastic cells are restrained inside the mammary ductal-lobular unit, whereas in invasive carcinoma neoplastic cells spread beyond that unit [15].

There is a long-standing believe regarding the histological origin of breast adenocarcinoma. Cancers originating from the ducts are known as ductal carcinomas, while those originating from the lobules are known as lobular. However, this has been challenged by Wellings and Jensen (1973) and Wellings et al. (1975). The new concept demonstrated that the breast carcinoma in situ and a wide variety of invasive breast adenocarcinoma arise from the terminal duct-lobular type regardless of the category of the histopathology. The use of ductal and lobular carcinoma division, by 


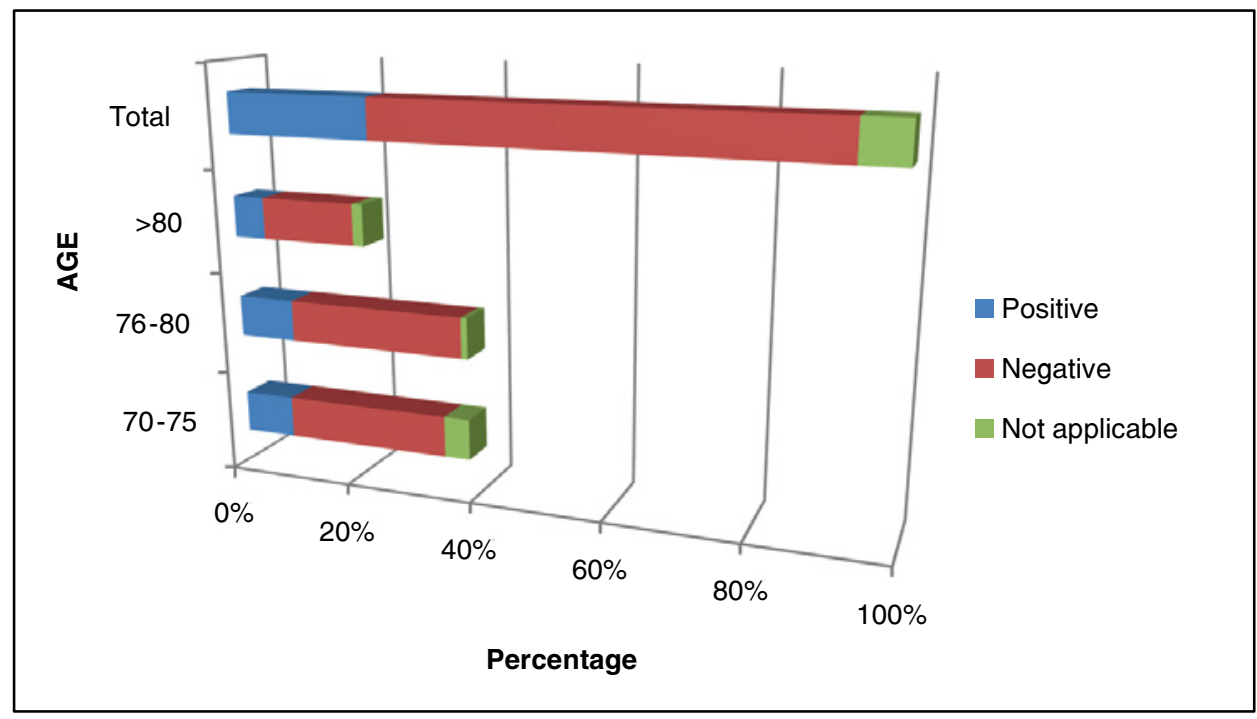

Figure 5. LVI: Lympho-vascular invasion in resected breast cancer of 170 patients aged above 70 years

no means is related to the origin of cancer within the mammary tissue. The histopathological classification of the breast adenocarcinoma should be determined by their distinct architectural features, cellular structures and immunohistochemistry [16-17].

The breast cancer is more aggressive in younger patients [18-19]. Our paper shows that $46 \%$ of all IDC cases were grade 2 , which accounted for $35 \%$ of all cases in the study cohort. Grade 1 and 2 IDC together accounted for $50 \%$ of all cases, and $68 \%$ in the invasive ductal carcinoma group. Therefore, our results are in line with the concept of that the disease is less aggressive in the older patients. The studies have shown that the comorbid conditions are associated with decreased overall survival in the breast cancer patients rather than presence of the cancer itself [20].

The literature mentions that median age of Caucasian patients with invasive lobular carcinoma is slightly higher than that of patients with invasive ductal carcinoma [21]. Mucinous carcinoma also occurs more frequently in older patients $[4,22]$. In our study only $1 \%$ of patients had invasive lobular carcinoma and $1.8 \%$ had mucinous carcinoma. Invasive lobular carcinoma and mucinous carcinoma usually present as small, slow-growing tumours with low grade histopathology, positive hormonal receptors, negative Her2 receptors and normal p53 [21-22]. Both of these types are known to have a better prognosis than invasive ductal carcinoma [18]. Tubular carcinoma is yet another breast cancer that is more likely to occur in older patients [22].

LVI is a significant predictor of poor prognosis in invasive breast cancer. In our study population, it was present only in less than one quarter of all cases. LVI is taken into account while planning a systemic adjuvant therapy, such as chemotherapy [23].

\section{Conclusion}

The available evidence suggests that there are potential age-related changes in the histology of breast cancer, as well as less aggressive forms of breast cancer in the elderly.

The results of the present study are in line with the current reports regarding cancer diagnosis in the older patients.

The breast cancer in not uncommon in the elderly and selection of treatment should be based on the histopathological type, overall medical condition, and not on the patient's age. The elderly women with a life expectancy of more than 10 years should be routinely considered in the mammography-based screening programs.

\section{References}

1. Elomrani F, Zine M, Afif M, et al. Management of early breast cancer in older women: from screening to treatment. Breast Cancer (Dove Med Press). 2015; 7: 165-171, doi: 10.2147/BCTT.S87125, indexed in Pubmed: 26185468.

2. Tesarova P. Specific Aspects of Breast Cancer Therapy of Elderly Women. Biomed Res Int. 2016; 2016: 1381695, doi: 10.1155/2016/1381695, indexed in Pubmed: 27807536.

3. Syed BM, Green AR, Paish EC, et al. Biology of primary breast cancer in older women treated by surgery: with correlation with long-term clinical outcome and comparison with their younger counterparts. $\mathrm{Br} \mathrm{J}$ Cancer. 2013; 108(5): 1042-1051, doi: 10.1038/bjc.2012.601, indexed in Pubmed: 23462719.

4. Rosen PP, Lesser ML, Kinne DW. Breast carcinoma at the extremes of age: a comparison of patients younger than 35 years and older than 75 years. J Surg Oncol. 1985; 28(2): 90-96, indexed in Pubmed: 2982064.

5. Jacquemier J, Seradour B, Hassoun J, et al. Special morphologic features of invasive mammary carcinomas in women under 40 years of age. Breast Dis. 1985; 1: 119-122.

6. Rochefordiere A, Asselain B, Campana F, et al. and Forquet A Age as prognostic factor in premenopausal breast carcinoma. Lancet. 1993; 341: 1039-1043 
7. Carter BJ. Long-term survivors of breast cancer. A qualitative descriptive study. Cancer Nurs. 1993; 16(5): 354-361, indexed in Pubmed: 8261383

8. Makki J, Myint O, Wynn AA, et al. Expression distribution of cancer stem cells, epithelial to mesenchymal transition, and telomerase activity in breast cancer and their association with clinicopathologic characteristics. Clin Med Insights Pathol. 2015; 8: 1-16, doi: 10.4137/CPath. S19615, indexed in Pubmed: 25624778

9. Makki J. Diversity of breast cancer: Histological subtypes and clinical relevance. Clinical Medicine Insights: Pathology. 2015; 8: 23-31.

10. Limite G, Di Micco R, Sollazzo V, et al. Clinically cNo breast cancer in elderly: what surgery? Int J Surg. 2014; 12 Suppl 2: S130-S134, doi: 10.1016/j.jjsu.2014.08.364, indexed in Pubmed: 25183642.

11. Lakhani SR, Ellis IO, Schnitt SJ, et al. Van de Vijver MJ, editors. WHO Classification of Tumours of the Breast. Fourth ed IARC; Lyon: 2012 ISBN; 13.

12. Balabram D, Turra CM, Gobbi H. Association between age and survival in a cohort of Brazilian patients with operable breast cancer. Cad Saude Publica. 2015; 31(8): 1732-1742, doi: 10.1590/0102-311X00114214 indexed in Pubmed: 26375651.

13. Sanguinetti A, Polistena A, Lucchini R, et al. Breast cancer in olde women: what factors affect the treatment? Int J Surg. 2014; 12 Supp 2: S177-S180, doi: 10.1016/j.ijsu.2014.08.346, indexed in Pubmed: 25157991.

14. Diab SG. Tumor Characteristics and Clinical Outcome of Elderly Women With Breast Cancer. Journal of the National Cancer Institute. 2000; 92(7): 550-556, doi: 10.1093/jnci/92.7.550.

15. Araújo T, Aresta G, Castro E, et al. Classification of breast cance histology images using Convolutional Neural Networks. PLoS One. 2017; 12(6): e0177544, doi: 10.1371/journal.pone.0177544, indexed in Pubmed: 28570557
16. Wellings SR, Jensen HM. On the origin and progression of ductal carcinoma in the human breast. J Natl Cancer Inst. 1973; 50(5): 1111-1118, indexed in Pubmed: 4123242

17. Wellings SR, Jensen HM, Marcum RG. An atlas of subgross pathology of the human breast with special reference to possible precancerous lesions. J Natl Cancer Inst. 1975; 55(2): 231-273, indexed in Pubmed: 169369.

18. Fisher ER, Osborne CK, McGuire WL, et al. Correlation of primary breast cancer histopathology and estrogen receptor content. Breast Cancer Res Treat. 1981; 1(1): 37-41, indexed in Pubmed: 7348564

19. Chen HL, Zhou MQ, Tian W, et al. Effect of Age on Breast Cancer Patient Prognoses: A Population-Based Study Using the SEER 18 Database. PLoS One. 2016; 11(10): e0165409, doi: 10.1371/journal. pone.0165409, indexed in Pubmed: 27798652.

20. Patnaik JL, Byers T, DiGuiseppi C, et al. Cardiovascular disease competes with breast cancer as the leading cause of death for older females diagnosed with breast cancer: a retrospective cohort study. Breast Cancer Res. 2011; 13(3): R64, doi: 10.1186/bcr2901, indexed in Pubmed: 21689398

21. Berg JW, Hutter RVP. Hutter RVP. Breast cancer CANCER. 1995; 75(1).

22. Diab S, Clark G, Osborne C, et al. Tumor Characteristics and Clinical Outcome of Tubular and Mucinous Breast Carcinomas. Journal of Clinical Oncology. 1999; 17(5): 1442-1442, doi: 10.1200/jco.1999.17.5.1442

23. Song YJu, Shin SH, Cho JS, et al. The role of lymphovascular invasion as a prognostic factor in patients with lymph node-positive operable invasive breast cancer. J Breast Cancer. 2011; 14(3): 198-203, doi: 10.4048/jbc.2011.14.3.198, indexed in Pubmed: 22031801 